\title{
A 8 years Old Girl Presented with Parry Romberg Syndrome attended at Shaheed Suhrawardy Medical College Hospital: A Case Report
}

\author{
Khan $\mathrm{EH}^{1}$, Rashid $\mathrm{MA}^{2}$, Moonmoon $\mathrm{TH}^{3}$, Ahmed $\mathrm{M}^{4}$, Tanim $\mathrm{B}^{5}$
}

\begin{abstract}
Parry-Romberg Syndrome is an uncommon, degenerative and poorly understood condition. It is characterized by a slow and progressive atrophy affecting one side of the face. Possible factors that are involved in the pathogenesis include trauma, viral infections, heredity, endocrine disturbances and auto-immunity. Characteristically the atrophy progresses slowly for several years and soon after it become stable. In this case report, the patient of 8 years old girl complaints of gradual wasting of left side of face for 1 year involving cheek, chin, pre-auricular area, forehead, left upper lip which reveals facial asymmetry and mild wasting of left side of face as well as tongue. There was focal alopecia and depression over left side of scalp. After four months back, there was a hypopigmented area over malar prominence of same side. She was diagnosed as Parry Romberg syndrome on the basis of history, clinical examination and investigation. Antinuclear antibody and Anti-Scl-70 antibody were positive. Histopathological diagnosis was compatible with localized scleroderma. The patient was treated with drugs, physical therapy including electric stimulation as well as exercise.
\end{abstract}

Keywords: Hemi facial atrophy, Parry-Romberg syndrome, treatment, progresive hemifacial atrophy, facial asymmetry, PHA, contralateral epilepsy

\section{Introduction}

Parry-Romberg Syndrome also known as Progressive Hemifacial Atrophy (PHA), is an uncommon degenerative condition characterized by slow and progressive atrophy which is generally involved unilateral, facial tissues including muscles, bones and skin ${ }^{1,2}$. It causes an aesthetic trouble and also this illness brings several functional and psychological problems when a symmetric face loses its identity $^{2}$.

The incidence and cause of this alteration is unknown. A cerebral disturbance on fat metabolism has been proposed as a primary cause $\mathrm{e}^{3,4}$. Trauma, viral infections, endocrine disturbances, auto-immunity and heredity are believed to be associated to the pathogenesis of the disease $\mathrm{e}^{5-9}$. Usually the onset of this syndrome occurs along first and second decades of life. The atrophy characteristically progress slowly during many years. Then it becomes stable ${ }^{10-12}$. Alterations concerning involvement, duration and deformity can stabilize in any stage of growing and development ${ }^{2-5}$. Patients, who manifest atrophy in early ages, have bigger repercussions ${ }^{11}$. This syndrome seems to have higher incidence in women ${ }^{1,3,7}$. The extension of the atrophy is frequently limited to one side of the face. The ipsilateral involvement of body is rare and only $2.5 \%$ to $10 \%$ of cases are described as being bilatera ${ }^{6}$. The most important features of this pathology are the enophthalmy, the deviation of mouth and nose to the affected side as well as unilateral exposition of teeth when lips are involved ${ }^{7}$.

In this case report an 8 years old girl with Parry-Romberg Syndrome was attended at a tertiary care hospital in Dhaka.

1. Dr. Ehsanul Haque Khan, Associate Professor, Department of Physical Medicine and Rehabilitation, Shaheed Suhrawardy Medical College, Dhaka

2. Prof. M.A. Rashid, Professor \& Head, Department of Physical Medicine and Rehabilitation, Shaheed Suhrawardy Medical College, Dhaka

3. Dr. Taslima Hoq Moonmoon, Assistant Professor, Department of Physical Medicine and Rehabilitation, Shaheed Suhrawardy Medical College, Dhaka

4. Dr. Monzur Ahmed, Assistant Registrar, Department of Physical Medicine and Rehabilitation, Shaheed Suhrawardy Medical College, Dhaka

5. Dr. Bidoura Tanim, Radiologist, Department of Radiology and imaging, National Institute of Ophthalmology \& Hospital, Dhaka 


\section{Case presentation}

A 8 years old girl studied at class II hailing from Shonargaon upazila under Narayanganj district 70 kilometres away from capital city Dhaka was admitted in the Department of Physical Medicine and Rehabilitation at Shaheed Suhrawardy Medical College and hospital, Dhaka on 8th August of 2012 with the complaints of gradual wasting of left side of face for one year involving cheek, chin, preauricular area, forehead and left upper lip. She was nonasthmatic, normotensive and nondiabetic.

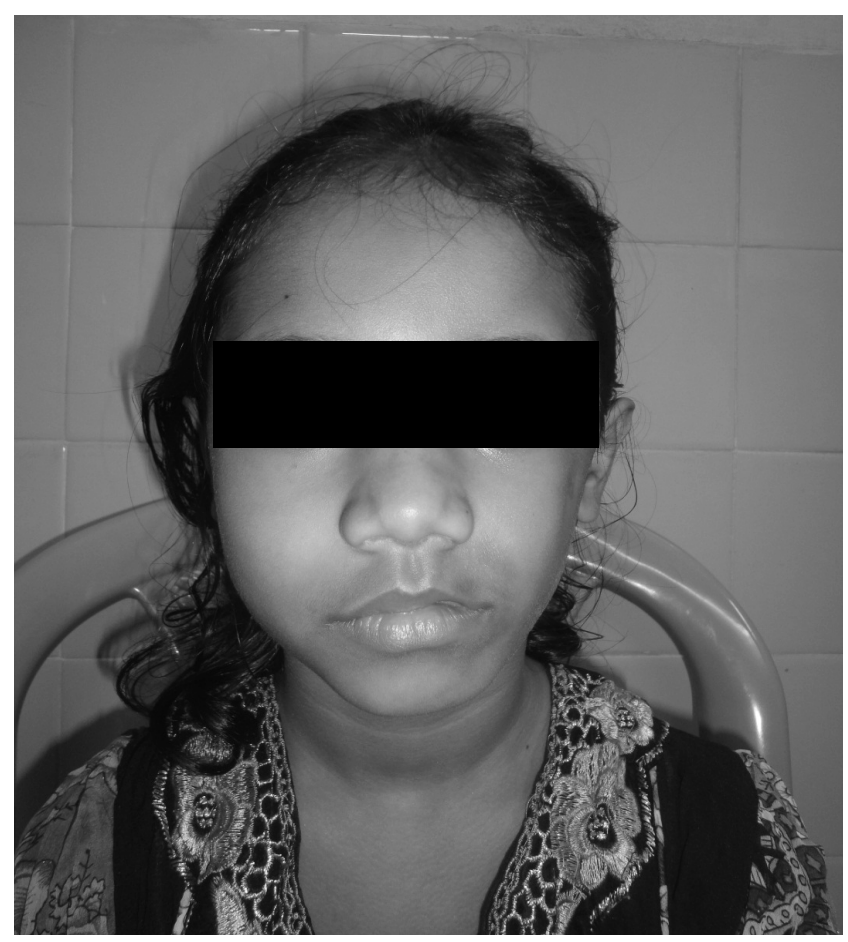

Figure I: a case of Parry-Romberg Syndrome

On quiry the patient had a history of focal alopecia and depression over left side of scalp four (4) months back which was persisted in same manner. The patient had no history of fever, headache, seizure, weakness of limbs, visual disturbance, difficulty in mouth opening or swallowing, arthritis or rash. The patient was born as full term baby with no history of birth trauma with perinatal asphyxia. General examination was revealed the facial asymmetry with mild wasting of left side of face and tongue. A hypopigmented area was detected over malar prominence of same side. There was a focal area of alopecia and depression over left side of scalp. Patient was mildly anaemic; however, the vital parameters were normal. All other systemic examinations were revealed normal.

According to statement of patient's mother the girl was relatively well 1 year back, since then wasting of left side of face was started which was insidious in onset. At first this was started at cheek. Then gradually spreaded over months to the chin, preauricular area, forehead, left ala of nose as well as on the left upper lip. The patient gave no history of trauma to face or on head. The bowel and bladder habbit were normal. With Above mentioned complaints the patient was admitted to this hospital.

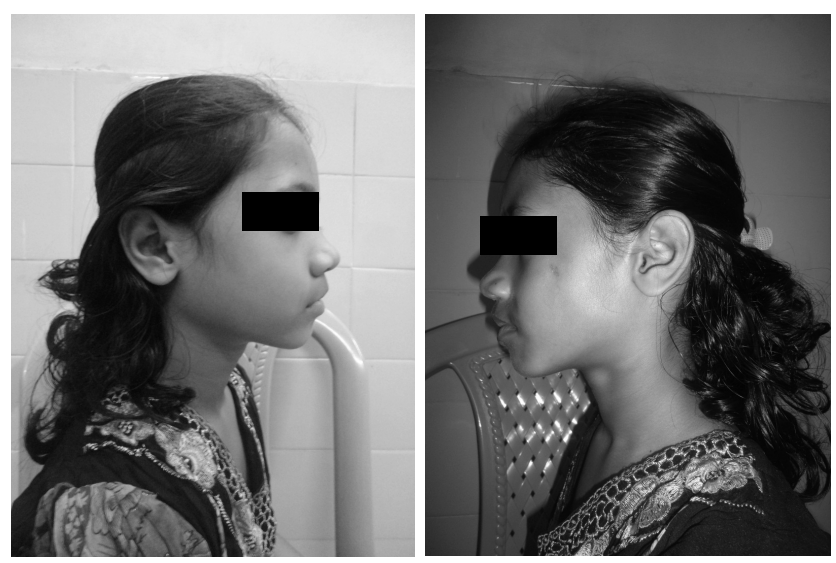

Figure II: Wasting of left side of face

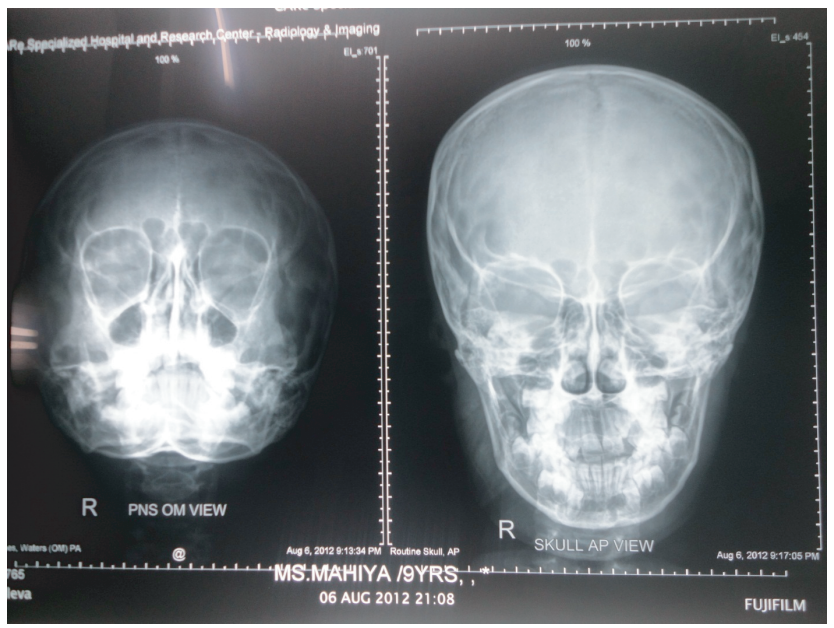

Figure III:X ray PNS OM view

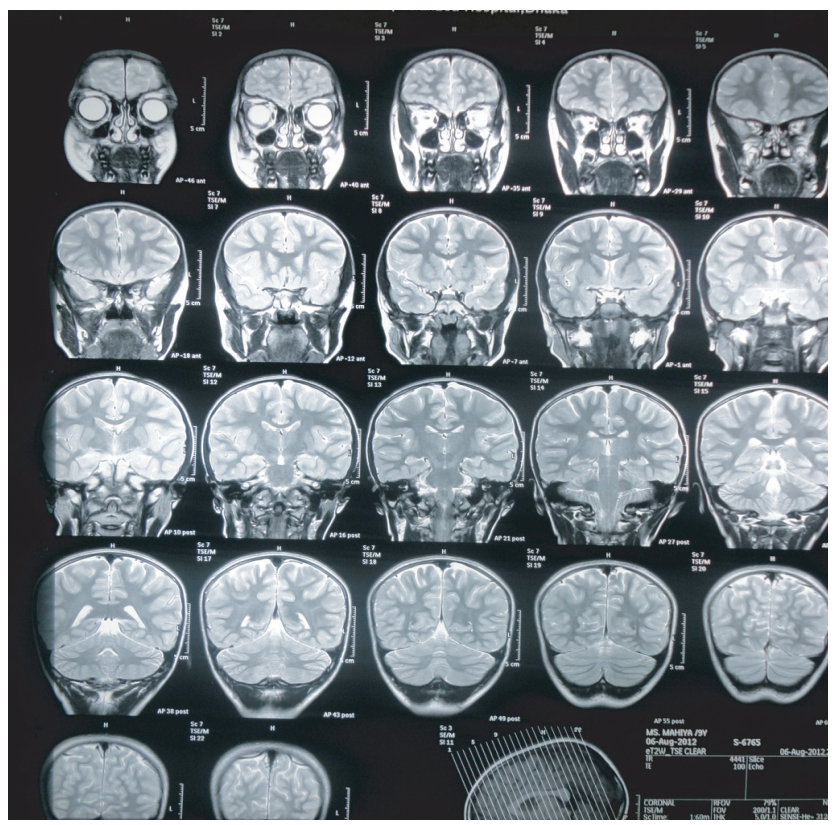

Figure IV: MRI of Brain 
During investigation CBC was found within normal limit; however, haemoglobin was below normal limit (10.5 $\mathrm{gm} / \mathrm{dL}$ ). Report of routine examination of urine, random blood sugar, serum creatinine level, SGPT, chest X-ray, echocardiography, X-ray PNS OM view as well as creatinine phosphokinase were found normal. MRI of brain was done revealed no abnormality. Among immunological test serum antinuclear antibody (ANA) by ELISA was positive; on the other hand anti-Sm/RNP antibody, antiSSA antibody, anti SSB antibody, Anti-Jo antibody was found negative. However, anti-Scl-70 antibody test was positive. Biopsy was taken from malar area which was shown thin epidermis. The dermis was revealed dense compact collagen fibers and moderate peri-vascular infiltrate of chronic inflammatory cells. Pilosebaceous units were small. Subcutaneous fat was not present. After getting all these finding it was confirmed that this was a case of Parry-Romberg Syndrome.

\section{Discussion}

Unilateral progressive atrophy of the face was first described by Parry in 1825 and Romberg in 1846. Eulenberg coined the term 'progressive facial hemiatrophy' in 1871. The term progressive hemi facial atrophy (PHA) is more widely accepted ${ }^{13}$. The disease manifests in the first or second decade of life with a slow progression over many years showing atrophy and then becomes stable ${ }^{14-17}$. In the present case the patient was at the age of 8 years. Duration and deformity can stabilize in any stage of growth and development ${ }^{14,18}$. There is involvement of the skin and subcutaneous fat, and on rare occasions also of the muscles and bones ${ }^{13}$.

Although, it is uncommon and generally unilateral ${ }^{18,19}, 5-$ $10 \%$ cases were described as being bilateral ${ }^{18}$. The present case was also shown the unilateral involvement. This finding correlates with the present case report. The extension of the atrophy is frequently limited to one side of the face, and the ipsilateral involvement of body is rare. Occular involvement is common, and the most frequent manifestation is enophthalmy, due to fat loss around the orbit. The eye usually works normally and the ears can be smaller than normal ones due to the atrophy ${ }^{14}$. Parry Romberg syndrome is found to be more common in females $^{19-21}$.

The etiology of the disease is unidentified. A cerebral disturbance on fat metabolism has been proposed as a primary cause $e^{20,22,23}$. Trauma, viral infections, endocrine disturbances, auto-immunity and heredity are believed to be also associated to the pathogenesis of the

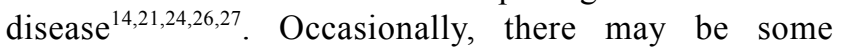
neurological complications, such as trigeminal neuralgia, facial paresthesia, severe headache and contralateral epilepsy ${ }^{16,18,26-29}$. Contralateral epilepsy is the most common complication as reported by Chbicheb et $\mathrm{al}^{29}$. Parry-Romberg Syndrome is a self-limiting condition and there is no cure. Patients, who manifest atrophy in early ages, have a better outcome ${ }^{16}$. Affected patients should have multidisciplinary attendance of physicians, surgeons, dentists, physiatrist and psychologists. The active stage of the disease is usually treated with corticosteroids and immunosuppressant therapy. Cases associated with Lyme disease have been treated with antibiotics like parenteral penicillin and ceftriaxone. Phototherapy with UV-A radiation $(340-400 \mathrm{~nm})$ has been tried with success as it has been known to induce matrix metalloproteinase 1 (MMP-1) to reverse the fibrosis, although the use is limited due to unpleasant adverse effects. Once the deformities have set in, plastic and reconstructive surgeries are recommended. Orthodontic treatment with hybrid appliances may be designed to manage the dental malocclusion $^{30}$.

\section{Conclusion}

Parry Romberg syndrome is a rare disease which may present with connective tissue, muscular, oral, neurological and ocular complications. It is a disfiguring disease of uncertain origin where early diagnosis and prompt management is essential for optimal quality of life. If diagnosed much earlier in life, the developing facial deformity could have been prevented. More research is necessary to assess safety and efficacy of management of this incurable disease.

\section{References}

1. Jurkiewicz MJ, Nahai F. The use of free revascularized grafts in the amelioration of hemifacial atrophy. Plast Reconstr Surg 1985;76:44-55 2. Lakhani PK, David TJ. Progressive hemifacial atrophy with scleroderma and ipsilateral limb wasting (Parry Romberg Syndrome). J R Soc Med 1984;77:138-9

3. Finesilver B, Rosow HN. Total hemiatrophy. JAMA 1938;5:366-8

4. Foster TD. The effects of hemifacial atrophy of dental growth. Br Dent J 1979; 146:148-50

5. Mazzeo N, Fisher JG, Mayer MH, Mathieu GP, Mcade FGG. Progressive hemifacial atrophy (Parry Romberg Syndrome). Oral Surg Oral Med Oral Pathol Oral Radiol Endod 1995;79:30-5

6. Miller MT, Sloane H, Goldberg MF, Grisolano J, Frenkel M, Mafee MF. Progressive hemifacial atrophy (Parry Romberg Disease). J Pediatr Oftamol Strabismus 1987;24:27-36

7. Pensler JM, Murphy GF, Muliken JB. Clinical and ultra-structural studies of Romberg's hemifacial atrophy. Plast Reconstr Surg 1990;85:669-76

8. Shaffer WG, Hine MK, Levy BM, eds. Textbook of oral pathology. Philadelphia: WB Saunders; 1983. p. 9-10

9. Zafarulla MY. Progressive hemifacial atrophy: a case report. Br J Ophthalmol 1985;69:545-7

10. Moore MH, Wong KS, Proudman TW, David DJ. Progressive hemifacial atrophy (Romberg's Disease): skeletal involvement and treatment. Br J Plast Surg 1993; 46: 39-44

11. Neville BW, Damm DD, Allen CN, Bouquout JE, eds. Patologia oral e Maxilofacial. Rio de Janeiro: Guanabara Koogan; 1998. p. 35

12. Roddi R, Riggio E, Gilbert PM, Houvius SER, Vaandrager JM, van der Meulen JCH. Clinical evaluation of techiniques used in the surgical treatment of progressive hemifacial atrophy. J Craniomaxilofac Surg. 2008;13(2):67-70 
13. Goldhammer Y, Kronenberg J, Tadmor R, Braham J, Leventon G. Progressive hemifacial atrophy (Parry-Romberg's disease) principally involving bone. J Laryngol Otol 1981, 95:643-647

14. Mazzeo N, Fisher JG, Mayer MH, Mathieu GP. Progressive hemifacial atrophy (Parry-Romberg syndrome) Case report. Oral Surgery, Oral Medicine, Oral Pathology, Oral Radiology Endodontology 1995;79(1):30-35

15. Moore MH, Wong KS, Proudman TW, David DJ: Progressivehemifacial atrophy (Romberg's Disease): skeletal involvementand treatment. Br J Plast Surg 1993, 46:39-44

16. Neville BW, Damm DD, Allen CN, Bouqout JE. Facilio Sugerica:Patologia oral e Maxilofacial Volume 1. 5th edition. Edited byGuanabara Koogan. Rio de Janeiro: Nike and Lidman; 1998:35-42 17. Roddi R, Riggio E, Gilbert PM, Houvius SER, Vaandrager JM, van der Meulen JCH: Clinical evaluation of techiniques used in the surgical treatment of progressive hemifacial atrophy. J Craniomaxilofac Surg 1994, 22:23-32

18. Lakhani PK, David TJ: Progressive hemifacial atrophy with scleroderma and ipsilateral limb wasting (Parry Romberg Syndrome) J R Soc Med 1984, 77:138-139

19. Jurkiewicz MJ, Nahai F: The use of free revascularized grafts in the amelioration of hemifacial atrophy. Plast Reconstr Surg 1985;76:44-55

20. Finesilver B, Rosow HN: Total hemiatrophy. JAMA 1938, 5:366-368

21. Pensler JM, Murphy GF, Muliken JB: Clinical and ultra-structural studies of Romberg's hemifacial atrophy. Plast Reconstr Surg 1990, 85:669-676

22. Miller MT, Sloane H, Goldberg MF, Grisolano J, Frenkel M, Mafee MF. Progressive hemifacial atrophy (Parry Romberg Disease). J Pediatr Oftamol Strabismus 1987, 24:27-36

23. Foster TD: The effects of hemifacial atrophy of dental growth. Br Dent J 1979, 146:148-150

24. Shaffer WG, Hine MK, Levy BM. Hemifacial atrophy. In Textbook of oral pathology Volume 1. 8th edition. Edited by John, S. Philadelphia: WB Saunders; 1983:9-10

25. Zafarulla MY. Progressive hemifacial atrophy: a case report. Br J Ophthalmol 1985;69:545-547

26. Gorlin RJ, Pinborg JJ. Parry Romberg syndrome. In Syndromes of the head and neck Volume 1. 4th edition. Edited by Randman, R.New York: McGraw Hill;1964:475-477

27. Roed-Petersen B. Hemifacial lipodystrophy-report of a case. Oral Surg Oral Med Oral Pathol 1979, 43:230-232

28. Sagild JC, Alving J. Hemiplegic migraine and progressive hemifacial atrophy. Ann Neurol 1985, 17:620

29. Chbicheb M, Gelot A, Rivier F, Roubertie A, HumbertClaude V, Coubes P, Echenne B: Parry-Romberg's syndrome and epilepsy. Rev Neurol 2005, 161:92-97

30. Madasamy R, Jayanandan M, Adhavan UR, Gopalakrishnan S, Mahendra L. Parry Romberg syndrome: A case report and discussion. J Oral Maxillofac Pathol 2012;16:406-10 